\title{
Lung metastasis after pneumonectomy: Is there a place for surgery?
}

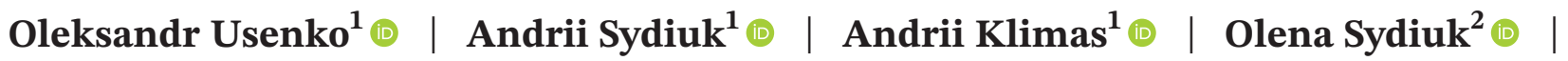

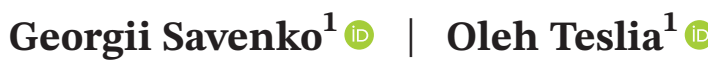

\author{
${ }^{1}$ Department of Thoracoabdominal \\ Surgery, Shalimov National Institute of \\ Surgery and Transplantology, National \\ Academy of Medical Sciences of \\ Ukraine, Kyiv, Ukraine \\ ${ }^{2}$ Department of Intensive Care \\ and Anaesthesiology, Shalimov \\ National Institute of Surgery and \\ Transplantology, National Academy \\ of Medical Sciences of Ukraine, Kyiv, \\ Ukraine

\section{Correspondence} \\ Andrii Klimas, Department of \\ Thoracoabdominal Surgery, Shalimov \\ National Institute of Surgery and \\ Transplantology, National Academy \\ of Medical Sciences of Ukraine, Kyiv, \\ Ukraine. \\ Email: klimas.andrew@gmail.com
}

\begin{abstract}
Resection of the contralateral lung after primary total pneumonectomy is a real surgical option for patients with secondary lung disease.
\end{abstract}

\section{K E Y W O R D S}

lung sarcoma, pneumonectomy, single lung resection

\section{1 | INTRODUCTION}

The choice of patient for a single lung resection is challenging for the surgeon. This report is presenting our experience in surgical treatment for patient with metastatic synovial sarcoma who initially underwent total left pneumonectomy and to identify possible predictors for the selection of patients who may undergo surgical treatment.

Synovial sarcoma of the lungs is an extremely rare pathology that is not commonly found in the daily clinical practice of thoracic and oncological surgeons. According to the world literature, it occurs only in $0.5 \%$ of cases of primary lung tumors. ${ }^{1}$ At the same time, global statistics from 170,000 patients with primary malignant lung tumors (PMLTs) showed that approximately $50 \%$ of patients in the future would have lung metastases, which would be treatable. ${ }^{2}$ In this case, data on the survival of patients after re-resection of the lungs for lung metastases of synovial sarcoma show an average duration without disease recurrence of up to 25 months. ${ }^{3}$ The level of 5-year survival in patients after lung resection for metastatic synovial sarcoma is up to $42.9 \%{ }^{4}$ This indicates aggressive biological behavior of this type of tumor, but the possibility of surgical treatment with radical resection of metastatic tumors can be quite effective and prognostically satisfactory. At the same time, the performance of repeated wedge resections on a lung usually does not cause big technical difficulties for the surgeon. According to the literature, the main intraoperative findings are pleural adhesions, which can sometimes require opening the pericardium and intrapericardial dividing of blood vessels. ${ }^{5}$ In modern literature, it is very rare to find reports of clinical cases of contralateral 
lung resection after pneumonectomy for malignant lung tumors. Because most patients in this category either have a metastatic disease that precludes surgical treatment or have a fairly low pulmonary reserve, the amount of parenchyma remaining after surgery is insufficient for adequate oxygenation of the patient, so such surgery may be associated with a high risk of severe respiratory failure and pulmonary complications. ${ }^{6}$ To date, there are no unified guidelines to address, which patients can be selected for re-surgical treatment. Assessment of pulmonary reserves, echocardiography, and oxygenation status can be effective predictors for lung resection in patients who have undergone total pneumonectomy. There is no research in world literature on the selection and treatment of patients who have undergone total pneumonectomy and require reresection of the lung. Therefore, we propose to consider the clinical case of treatment for a patient with a tumor in the right lung after a left pneumonectomy.

\section{CASE REPORT}

The 52-year-old patient in 2016 was admitted to the O.O. Shalimov National Institute of Surgery and Transplantology with complaints of shortness of breath during light exercise and chest pain. At the same time, a CT scan showed that the left hemithorax was occupied by an inhomogeneous tumor with a size of $17.5 \times 20 \times 26 \mathrm{~cm}$, which pushed the mediastinum to the right, though with no signs of metastases (Figures 1 and 2: CT scan; Tumor of the left hemithorax).
A cardiac ultrasound showed that the pulmonary artery pressure was normal at $28 \mathrm{mmHg}$, and the fraction of left ventricular ejection was $73 \%$. Examination of arterial blood gases yielded: pO2 - $76.1 \mathrm{mmHg}, \mathrm{pCO} 2$ $32.6 \mathrm{mmHg}$, venous blood pO2 - $40.8 \mathrm{mmHg}$, and pCO2 - $40.1 \mathrm{mmHg}$. No changes in the general and biochemical analysis of blood were revealed.

Preoperative studies of pulmonary function showed obstructive changes. Forced expiratory volume 1 was 0.94 L. (32.4\%), maximum vital volume was $1.58 \mathrm{~L}$ (45.4\%), and forced lung volume was $1.58 \mathrm{~L}(42 \%)$. With these indicators of pulmonary function, the performance of the left pneumonectomy looked doubtful, because of the high risks for developing postoperative respiratory failure. We supposed, however, based on CT modeling, the parenchyma that would be removed was not functional due to total atelectasis of the left lung. Moreover, the removal of a large tumor mass and returning of the mediastinal organs to a more natural physiological location could improve cardiopulmonary function in the future.

So, taking all of this into account, we decided to perform a pneumonectomy. Thus, during hospitalization, a transpericardial left total pneumonectomy was performed as planned. Given the large volume of the tumor mass and compression of the mediastinal organs, we chose a clamshell thoracotomy, which includes a bilateral thoracotomy with sternotomy in the fifth intercostal space. See intraoperative images (Figure 3: Intraoperative view of Clamshell approach, Figure 4: View of the operating field after intrapericardial left pneumonectomy, Figure 5: View removed the tumor).

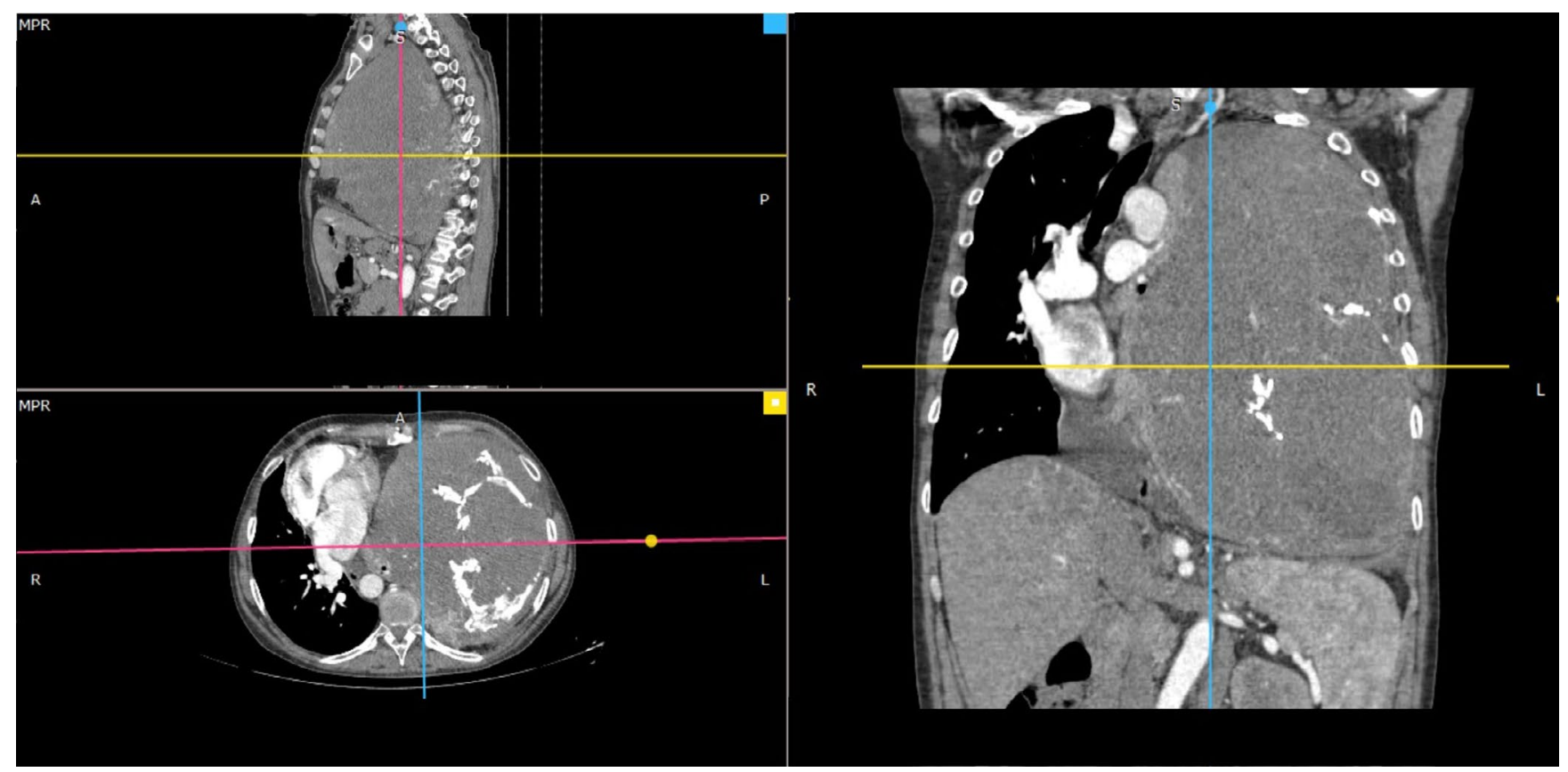

FIG URE 1 CT scan. Tumor of the left hemithorax 


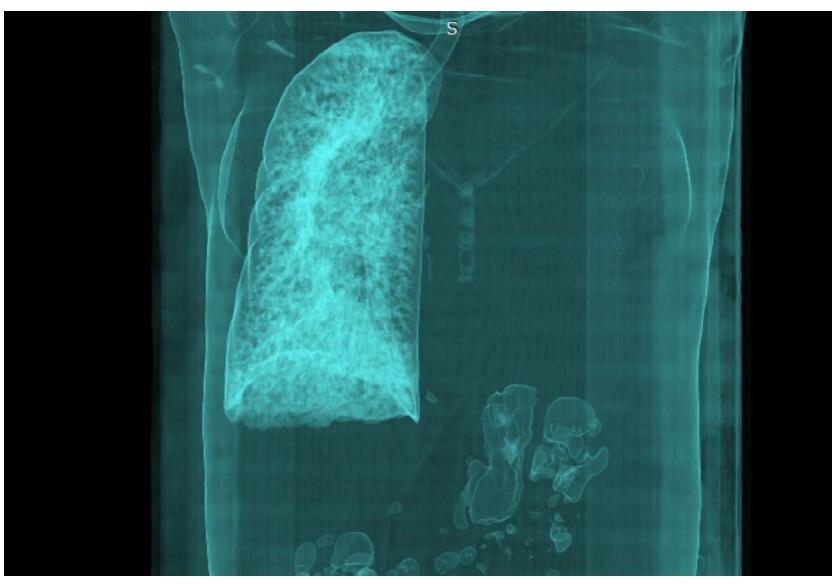

FI G URE 2 CT scan. Lack of lung tissue due to tumor lesions

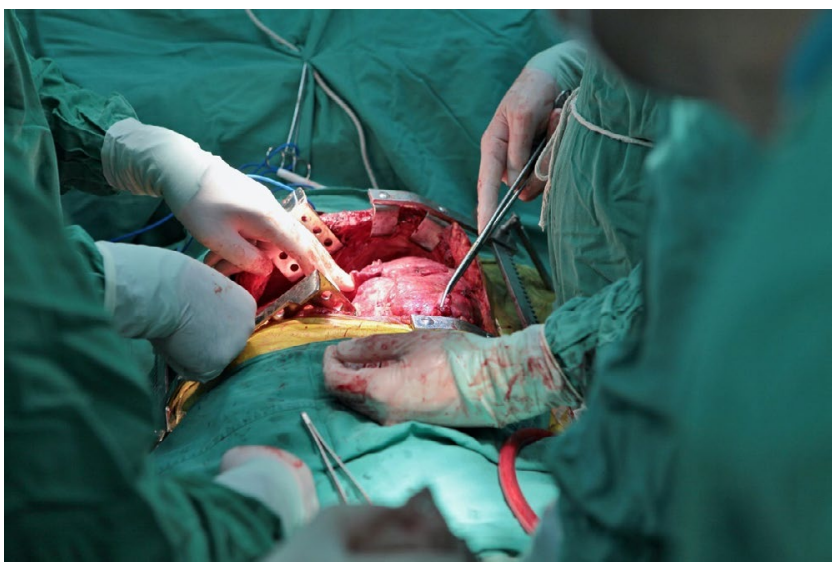

F I G URE 3 Intraoperative view of Clamshell approach

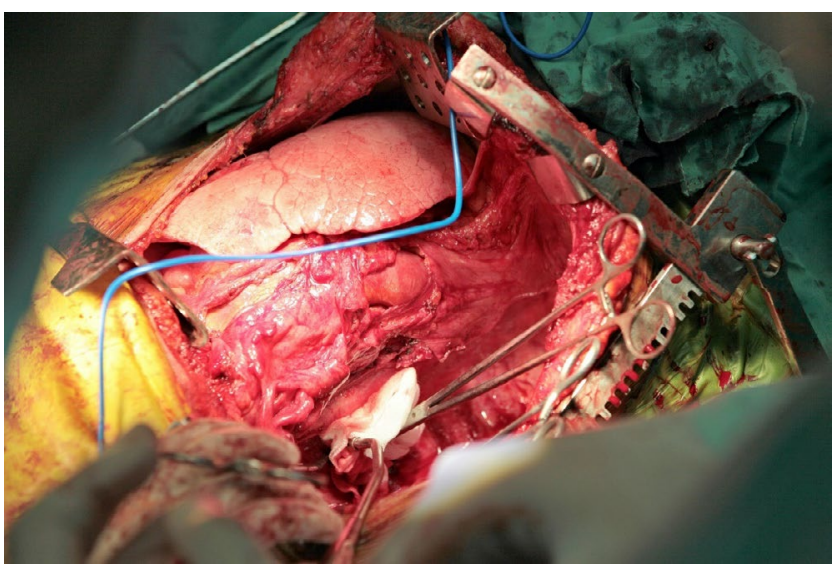

F I G URE 4 View of the operating field after intrapericardial left pneumonectomy

As a result, the patient was diagnosed with synovial sarcoma of the left lung T2bN0M0 stage III.

In the postoperative period, the patient received three courses of chemotherapy (endoxan, doxorubicin,

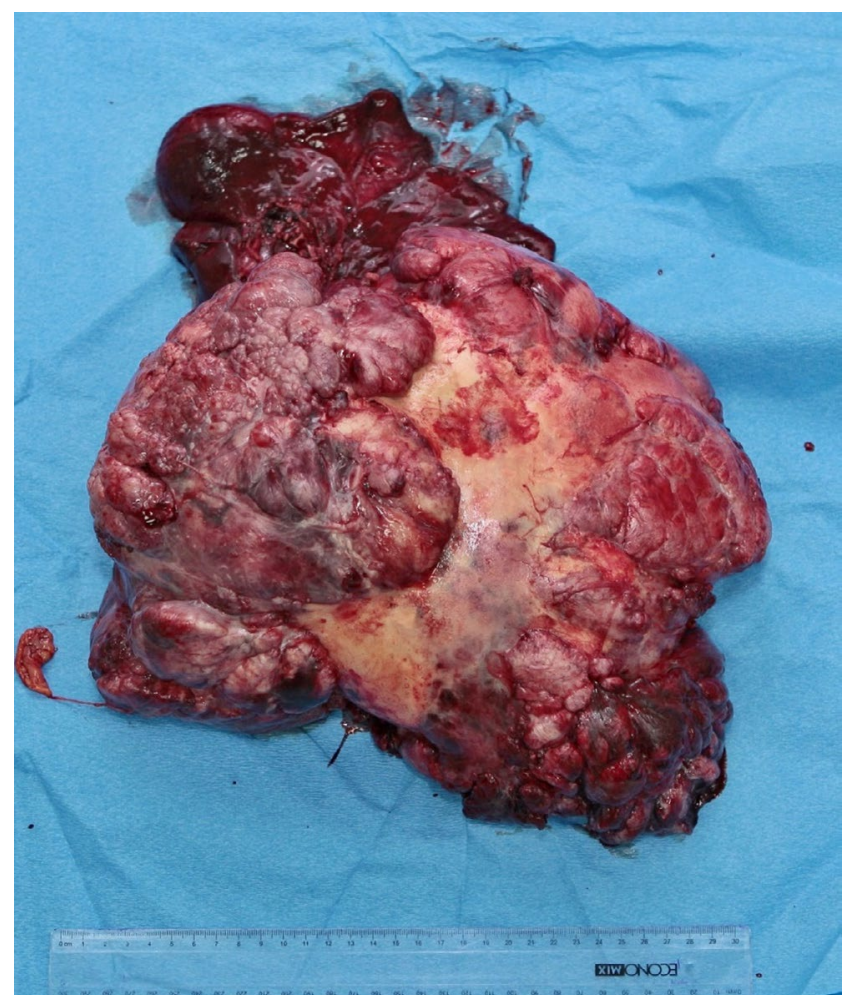

F I G URE 5 View removed the tumor

vincristine, and dacarbazine). There was no respiratory failure or pulmonary hypertension in the postoperative period.

Follow-up CT scans of the abdomen, chest, and pelvis with IV contrast were performed every 6 months.

Five years after the initial surgery, the patient began to complain of intermittent pain in the upper right half of the chest. CT scan revealed a tumor $150 \times 80 \times 100 \mathrm{~mm}$ in the upper right lung lobe, which is adjacent to the costal pleura.

CT signs of 3-D formation of the right lung (Figures 6 and 7: CT scan; View of the right lung metastasis).

Based on this, the following diagnosis was made: synovial sarcoma of the left lung T2bNOM0 stage III (after surgery and chemotherapy [2016]) Rec. metastasis of the right lung.

To determine the possibility of surgical treatment for the patient, a full list of necessary studies was performed, including respiratory function, echocardiography, electrocardiogram, arterial and venous blood gas exchange, clinical, and biochemical blood tests.

Preoperative studies of pulmonary function showed minor obstructive changes. Pulmonary reserve was better, even compared to preoperative parameters before the primary pneumonectomy: forced expiratory volume 1 was $1.66 \mathrm{~L}$ (64\%), maximum vital volume was $4.45 \mathrm{~L}$ (119\%), and forced lung volume was $3.12 \mathrm{~L}$ (87\%).

A cardiac ultrasound showed that pulmonary artery pressure was $34 \mathrm{mmHg}$, and the left ventricular ejection 


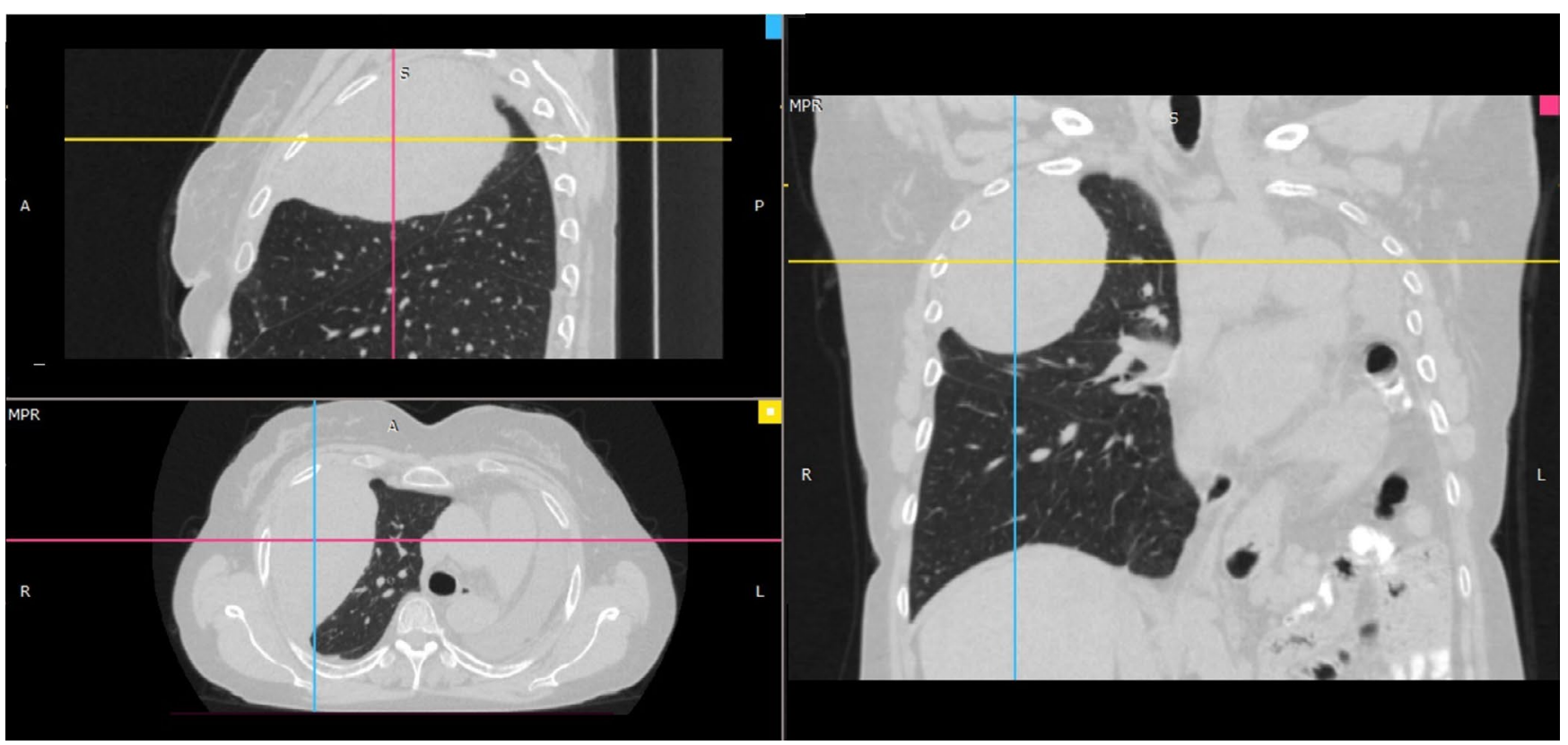

F I G URE 6 CT scan. View of the right lung metastasis

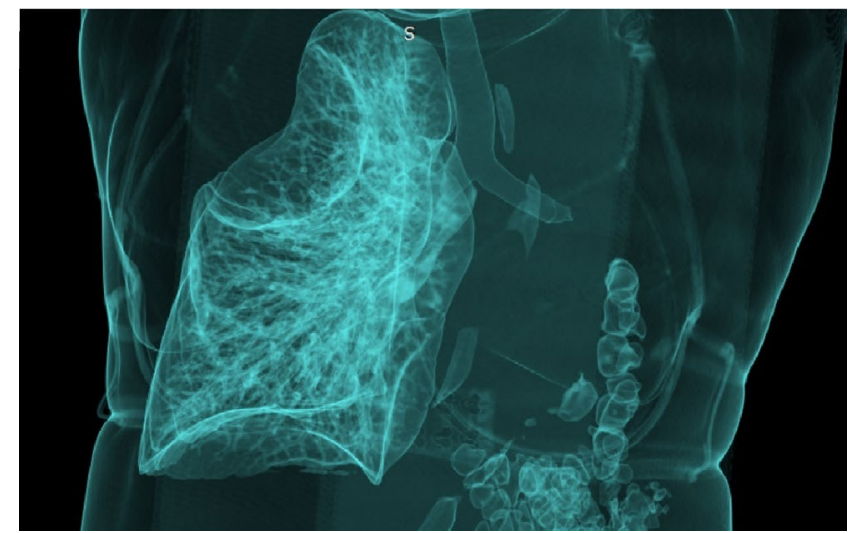

F I G U RE 7 CT scan. Lack of lung tissue due to tumor lesions

fraction was 58\%. Examination of arterial blood gases showed the following: pO2 was $101 \mathrm{mmHg}, \mathrm{pCO} 2$ was $31.0 \mathrm{mmHg}$, venous blood pO2 was $40.1 \mathrm{mmHg}$, and pCO2 was $39.8 \mathrm{mmHg}$. No changes in the general and biochemical analysis of blood were revealed.

Based on this assessment, we considered that the patient would be able to undergo right lobectomy or wedge resection of the right upper lobe. Thus, a right thoracotomy in third intercostal space and wedge resection of the right upper lobe with tumor was performed (Figure 8: View of the operating field after resection of the upper lobe of the right lung; Figure 9: View removed the tumor).

The postoperative period was uneventful. Examination of arterial blood gases yielded the following: pO2 was $207 \mathrm{mmHg}$, pCO2 was $33 \mathrm{mmHg}$, venous blood pO2 was $40.4 \mathrm{mmHg}$, and $\mathrm{pCO} 2$ was $33.5 \mathrm{mmHg}$.

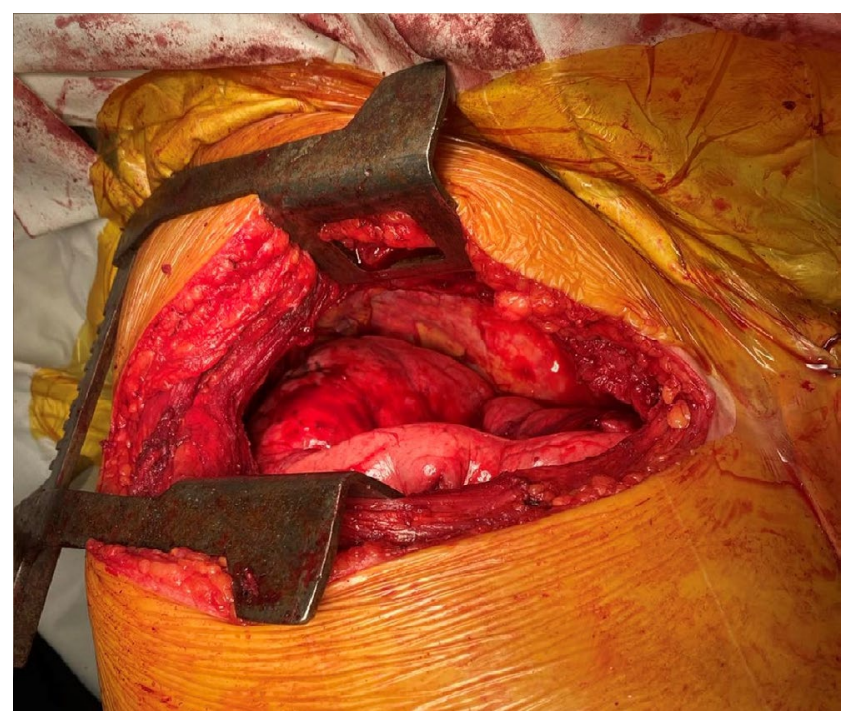

F I G URE 8 View of the operating field after resection of the upper lobe of the right lung

Pathology report: In the material of recurrencemonophasic synovial sarcoma.

On the 8th postoperative day, the patient was discharged from the hospital in satisfactory condition.

\section{DISCUSSION}

Due to the fact that surgical treatment of isolated metastatic tumor of synovial sarcoma is mainly a measure to extend life expectancy, wedge lung resection or lobectomy is a justified surgical procedure. However, according to 


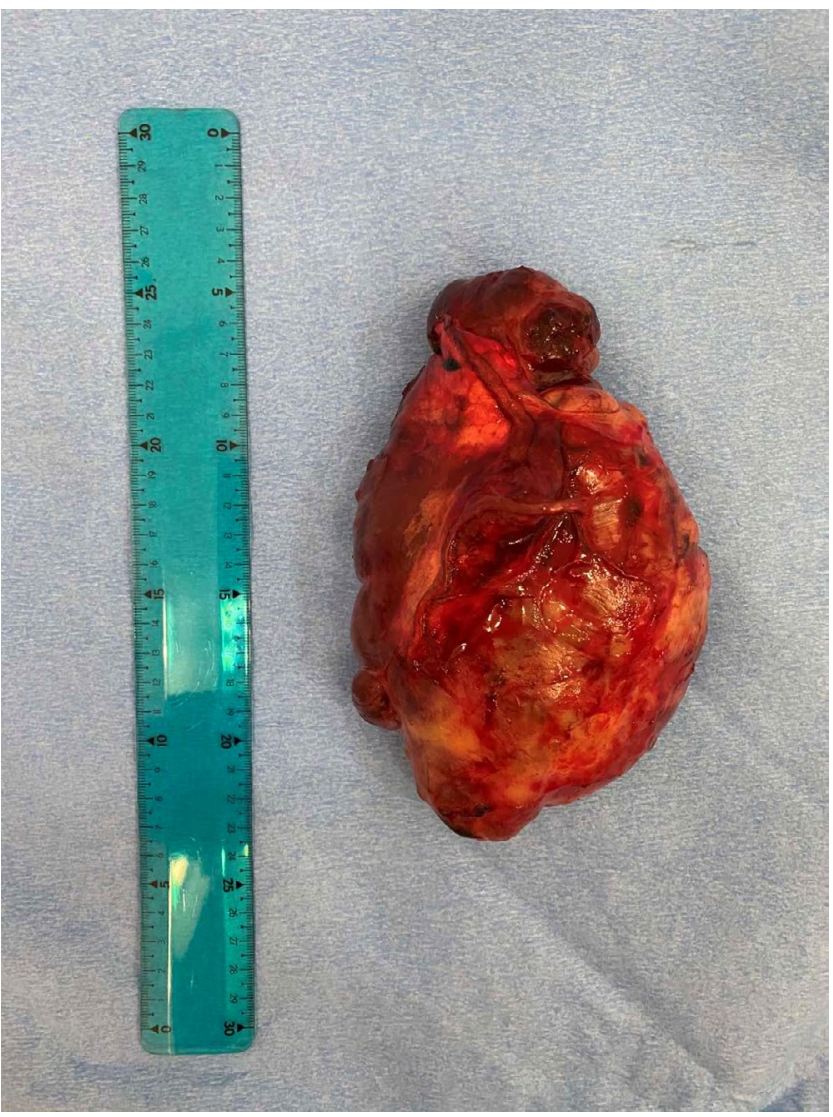

FIG URE 9 View removed the tumor

some authors, this decision may be controversial in patients who have already undergone total pneumonectomy. ${ }^{6}$ At the same time, there are recommendations on the possible use of systemic therapy in cases of metastatic sarcoma of the lung, namely in the form of the use of sunitinib, pazopanib, and pembrolizumab. However, the use of systemic therapy in literature thus far has poor survival results. We therefore believe that the use of surgery is more justified. Most reports and articles available in modern literature are not full-fledged studies, but only reports of clinical cases and do not have a large sample of patients. This means that the decision to perform surgery will be based only on the personal experience and understanding of the patient's multidisciplinary team of doctors. ${ }^{7,8}$

We therefore believe that in complex cases where there is a need for surgical treatment of metastatic lung disease in patients who have undergone pneumonectomy; the correct choice for the patient is to undergo further surgery. Although to date there is no unified protocol and criteria for selecting patients, we believe that the main predictors of postoperative cardiopulmonary complications are the extent of remaining parenchyma, echocardiography, pulmonary artery pressure, left ventricular ejection fraction, and blood gas exchange rates. In our case, both before and after primary surgery and after the secondary resection of the left lung, all of these indicators remained at a fairly good level, which allowed us to ensure a good postoperative quality of life for the patient and allowed us to achieve a satisfactory result of treatment.

In our opinion, resection of the contralateral lung after primary total pneumonectomy is a real surgical option for patients with secondary lung disease. The main indicators of the development of postoperative respiratory and heart failure are pulmonary function, echocardiography, and blood gas exchange.

\section{ACKNOWLEDGMENTS}

We would like to thank "Empire English School” https:// englishempire.com.ua/ for English language correction.

\section{CONFLICTS OF INTEREST}

None declared.

\section{AUTHOR CONTRIBUTIONS}

OU: supervised the project. AS: conceived the original idea, supervised the project, and is the chief surgeon of the performed operation. AK: prepared and wrote the manuscript, contributed to the design of the manuscript, and was engaged in pre and postoperative treatment of the patient. OS: assessed the results arterial blood gases and assessed the indicators of pulmonary function and provided the patient with anesthesia. GS: performed the measurements, contributed to the design, to the analysis of the results, and to the writing of the manuscript. OT: performed the measurements, contributed to the design, to the analysis of the results, and to the writing of the manuscript.

\section{CONSENT}

Informed consent obtained for research: All participants provided written informed consent prior to enrollment in the study. Informed consent obtained for publication of a case report: Written informed consent was obtained from the patient for the publication of this case report.

\section{DATA AVAILABILITY STATEMENT}

Data available on request from the authors. The data that support the findings of this study are available from the corresponding author upon reasonable request.

\section{ORCID}

Oleksandr Usenko (1) https://orcid. org/0000-0001-8074-1666

Andrii Sydiuk (1) https://orcid.org/0000-0001-7325-7104 Andrii Klimas (D) https://orcid.org/0000-0001-5677-0424 Olena Sydiuk (D) https://orcid.org/0000-0001-8522-7121 Georgii Savenko (1) https://orcid.org/0000-0002-8454-1992 Oleh Teslia (1) https://orcid.org/0000-0001-9119-0177 


\section{REFERENCES}

1. Pandey L, Joseph D, Pasricha R, Gupta MK. Primary synovial sarcoma of the lung: a rare presentation, diagnostic dilemma and review of literature. BMJ Case Rep. 2020;13:e237678.

2. Battafarano RJ, Force SD, Meyers BF, et al. Benefits of resection for metachronous lung cancer. J Thorac Cardiovasc Surg. 2004;127:836-842.

3. Jedlicka V, Dolezel J, Vlcek V, et al. Multiple lung metastasectomy for the poor differentiated metastatic synovial sarcoma. Rozhl Chir. 2007;86:85-88.

4. Kimura H, Suzuki M, Ando S, et al. Pulmonary metastasectomy for osteosarcomas and soft tissue sarcomas. Gan to Kagaku Ryoho. 2004;31:1319-1323.

5. Pablo A, Lozanoa O, Crespob I, Muñoz-Gonzáleza N, Embún R. Second lung lobectomies: are they safe and feasible? Arch Bronconeumol. 2018;54:227-228.

6. Yunpeng L, Peipeng C, Zhiguang Y, Peng Z, Rui G, Guoguang S. Right lower lobectomy eight years after left pneumonectomy for a second primary lung cancer. J Cardiothoracic Surg. 2013;8:46.
7. Quiroga J, Prim JMG, Moldes M, Ledo R. Middle lobectomy after pneumonectomy. Case study. Asian Cardiovasc Thorac Ann. 2009;17:300-301.

8. Baysungur V, Okur E, Tuncer L, Halezeroglu S. Sequential right upper sleeve lobectomy and left pneumonectomy for bilateral synchronous lung cancer. Eur J Cardiothoracic Surg. 2009;35:743-744.

How to cite this article: Usenko O, Sydiuk A, Klimas A, Sydiuk O, Savenko G, Teslia O. Lung metastasis after pneumonectomy: Is there a place for surgery? Clin Case Rep. 2021;9:e04954. https:// doi.org/10.1002/ccr3.4954 